\title{
From Ruthenium Complexes to Novel Functional Nanocomposites: Development and Perspectives
}

\author{
Karen Segala and Angela S. Pereira \\ Additional information is available at the end of the chapter
}

http://dx.doi.org/10.5772/46244

\section{Introduction}

Nanotechnology is one of the most widespread topics for current development in fundamentally all research areas. Along with polymer science that is also one of the leading fields and their studies cover a broad range of topics. This would include nanoelectronics as the critical scale for modern devices is now below $100 \mathrm{~nm}$. Other research areas may include polymer-based biomaterials, such as miniemulsion particles for drug delivery or tissue engineering, self-assembled layer-by-layer polymer films, electrospun nanofibers and imprint lithography.

Although the terminology "Nanotechnology" is quite recent, prior polymer science studies involving nanoscale dimensions were used. For example, phase separated polymer blends regularly acquire nanoscale phase dimensions; asymmetric membranes often have nanoscale void structure; miniemulsion particles can be synthesized below $100 \mathrm{~nm}$ and interfacial phenomena in blends and composites involve nanoscale dimensions. At times, amphiphilic macromolecules are used to modify the nanoparticles surface. The most common functionality of these types of polymers is a lipophilic part intercalated with the existing aliphatic chains at the nanoparticles surface, covering, or maybe even completely encapsulating the original passivated nanoparticle.[1,2] This type of encapsulation has been described for copolymers [3, 4] and phospholipids,[5-7], inter alia and takes advantage of the hydrophobic colloidal stability of organically passivated nanoparticles (NPs) to prepare polymeric nanocomposites. In this chapter we plan on reviewing various nanocomposites using a polymer-based matrix with transition metal complexes, namely ruthenium based complexes, and a wide range of inorganic nanoparticles with varying optical, antimicrobial and magnetic properties. These nanocomposites have potential applications in biomedical implants as well as small devices for clinical applications. 


\section{Metallopolymers}

Recent interest in functional polymer matrix based nanocomposites has emerged with great importance in many fields of scientific research as well as in industrial applications, which will increase greatly due to the variety of possible modifications in the chemical and physical properties of these materials.[8] This well-known interest in soft functional materials, led to the growing realization that the presence of metal centers in macromolecular materials can result in enhanced novel properties while maintaining the capacity of polymerizing through classic processing methods. Metal centers have been neglected as important structural components of synthetic polymers although they play a key role in determining the functions of many extended solids and biological macromolecules. The metallopolymer field has been delayed due to synthesis and characterization problems, such as what procedures to use, purification issues and a lack of commercially available starting reagents. Most of the classic polymerization procedures used in pure organic monomers originated inefficient or undesirable side reactions with the presence of the metal centers. These classic procedures originated low molar mass metallopolymers, contaminated by structural defects or missing conclusive characterization. The end of last century dictated the beginning of high molar mass metallopolymers with defined microstructures. Most of the synthetic strategies used are either compatible with the presence of coordinated metal centers or with pendant ligands that tolerate the consequent incorporation of metal ions.[9-11] This progress has been supported by the discovery and expansion of new characterization techniques, such as matrix-assisted laser desorption/ionization-time of flight spectroscopy or electrospray ionization mass spectrometry, as well as the rekindling of more traditional methods, such as analytical ultracentrifugation, leading to a vast collection of metal containing polymers that display an array of bonding modes and an assortment of structures. The ability to prepare metallopolymers with a variety of structures has fuelled efforts to improve the efficiency and control of synthetic procedures in order to create scaled-up, well-defined materials. These accomplishments lead to a range of potential applications which have now emerged, and the aim of this chapter is to illustrate selected recent advances of the use of metallopolymers in sync with inorganic nanoparticles to produce nanocomposites with varying antiseptic, optical and magnetic properties. These nanocomposites have potential applications in biomedical implants as well as small devices for clinical applications.

Network polymers based on styrene, prepared by well-developed suspension polymerization processes, retain many of their qualities for a microcomposite host matrix. The many advantages include facile preparation, controlled surface area and porous structure, good thermal resistance and reasonable chemical inertness.[12] Styrenedivinylbenzene copolymers have been the subject of several studies. Mahdavian et al. described an easy and efficient method for preparing polymer-supported chiral copolymers of styrene-divinylbenzene, which can be used in chromatographic columns packing.[13] Crosslinked copolymers prepared from styrene-divinylbenzene are of particular interest when used in the preparation of ion exchange resins by the introduction of various functional groups (polar or not) as alkyl, benzoyl, acetyl, hydroxymethyl and sulfonic 
derivatives.[14] Their main applicability is in catalytic supports and solid-phase extraction. The efficiency of sulfonate agents and their effects on the morphology of styrenedivinylbenzene beads have been investigated.[15] The authors found that the use of acetyl sulfate as a sulfonate agent preserved the spherical morphology of the beads.

Polymers based on the application of coordination forces have been prepared recently. The first direct synthesis of a polymer containing a transition metal complex gave rise to a coordination polymer based on ruthenium(II)-terpyridine complexes.[16,17] The combination of conventional polymers to metal centers generates intrinsic properties of the metal, retaining the properties of the conventional polymer. A new property acquired due to the metal center, is the electroactivity amongst all the transition metals, and the ruthenium has been widely used by coordination chemists mainly due to its ease of forming extremely stable complexes, especially with pyridine ligands and their derivatives.[18]

\section{Ruthenium (II) complexes: a brief history}

Ruthenium based metal complexes have shown a plethora of uses and applications. Namely, complex structures in the presence of a metal center containing ruthenium have shown good results in biological applications.[19-21] Coordination compounds of formula trans- $\left[\operatorname{Ru}_{2}(\mathrm{~L})_{4}\right]$, where $(\mathrm{X})=\mathrm{Cl}, \mathrm{Br}$, and $\mathrm{I},(\mathrm{L})$ one monodentated ligand (Figure 1) are extremely well known in literature and many compounds containing pyridine groups and their derivatives have been prepared and characterized.[22-24]

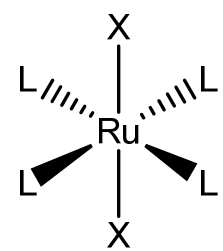

Figure 1. Molecular structure for ruthenium (II) metal complexes, where $\mathrm{L}$ is the different ligands monodentate and $\mathrm{X}$, the halogens $\mathrm{Cl}, \mathrm{Br}, \mathrm{I} .[25]$

The first studies were those with the synthesis of coordination complexes with four pyrrole group substituents. In 1996, progress was made in the synthesis and characterization of copper (I) complexes containing four tetranuclear pyrrole substituents attached to the pyridine ligand. The aim of the complex synthesis was to electropolymerize in the form of a copolymer, but the results were not encouraging and the authors remained focused only on the synthesis of the ruthenium complexes.[26] The preparation of a series of new electropolymerizable complexes with the general formula trans-[RuX $\left.\mathrm{R}_{2}(\mathrm{~L})_{4}\right]$ was achieved.[27, $28]$ The preparation and full characterization of poly-trans-[ $\left.\mathrm{RuCl}_{2}(\mathrm{pmp})_{4}\right]$ (pmp=3-(pyrrol-1ylmethyl) pyridine) was reported and its applicability demonstrated in the preparation of modified electrodes.[27, 29]

In order to fully understand the electropolymerization process and to determine the optimized electrochemical parameters for the achievement of a good film, electrochemical 
studies were made on trans-[ $\left.\mathrm{RuCl}_{2}(\mathrm{pmp})_{4}\right]$. In 1997, the preparation of electrodes modified by electropolymerization of poly-trans $\left[\mathrm{RuCl}_{2}(\mathrm{pmp})_{4}\right]$ using galvanostatic and potenciometric techniques was accomplished.[28] Studies show that water-soluble ruthenium complexes are of high therapeutic value due to their capacity to interfere with nitric oxide (NO) in biological systems.[30] On the other hand, the complex trans-[ $\mathrm{RuCl}_{2}$ (vpy)4] (vpy=4vinylpyridine),[31] composed of four groups, which are easily polymerized producing electroactive adherent films, compared to films made from the linkers vinylpyridine and vinylterpyridine, were also prepared.[32,33] Previous studies have shown that the complex trans-[ $\left.\mathrm{RuCl}_{2}(\mathrm{vpy})_{4}\right]$ can be electropolymerized on different substrates, including inert materials such as $\mathrm{Pt}$ and $\mathrm{Pd}$,[31] ferrous alloys[34, 35] and stainless steel.[36] Studies of cyclic voltammetry, electrochemical crystal microbalance quartz and Raman spectroscopy revealed the results of electropolymerization of the complex trans-[ $\left.\mathrm{RuCl}_{2}(\mathrm{vpy})_{4}\right]$ in $\mathrm{Au}$ and Pt electrodes in particular the effects of the polymerization potential on the characteristics of the film formed, and especially the understanding of the key processes involved in electropolymerization.[37]

Much of the recent work on polymer substrates has been focused on the structure of the polymeric matrix for subsequent complex formation with a metal ion. Antony et al. studied the synthesis and catalytic properties of poly-(styrene-divinylbenzene) supported by ruthenium (III complexes.[38] Styrene-divinylbenzene copolymers, with its reactive groups, have often been used as ligands with chelating properties. When reacted together with styrene (sty), divinylbenzene (DVB) can be used as a reactive monomer in polyester resins. The resulting cross-linked polymer is mainly used for the production of ion exchange resin. The authors showed that by a simple method, the new polymer of ruthenium catalyst was effective in the epoxidation of styrene and cyclic olefins. The facile preparation and recyclability of these catalysts should provide a useful strategy for oxidation of organic substrates under controlled experimental conditions.

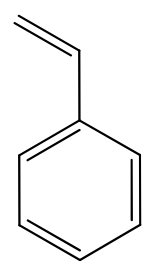

styrene
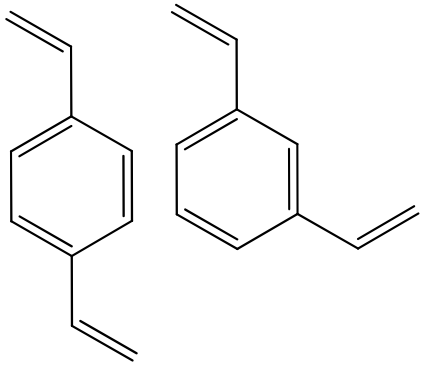

divinylbenzene<smiles>C=Cc1ccncc1</smiles>

4-vinylpyridine

Figure 2. Chemical structures of monomers commonly used along with ruthenium complexes to form metallo-co-poymers.

However, few thermal studies were found in the literature involving copolymers of vinylpyridine and divinylbenzene. The vinylpyridine can be chemically modified by oxidation, producing vinylpyridine N-oxide. These modified materials can be used as 
catalyst supports and ion exchange resins to remove heavy metals due to the presence of oxidized vinylpyridine groups.[39] The covalent incorporation of the transition metal complexes in the polymer network should be accompanied by benefits in biological systems.[40] There is great interest in biomedicine and bio-nanotechnology in studies involving supported metal complexes as enzyme inhibitors.[41] Metals such as ruthenium, osmium, and iridium are capable of forming stable complexes which are not involved in biological environments, thereby expanding the coordination modes limited to carbon. This provides new opportunities for the construction of small molecular structures that cannot be occupied by purely organic compounds.[42] Recent studies have shown the importance of the presence of ruthenium structures in biological research involving cancer treatment.[43] Lately, many studies are being conducted using ruthenium complexes in nanocomposites and biomaterials. Such studies have shown that the nanocomposite containing the complex can be used as nanodrug, for targeting cancer, and intracellular labeling.[44] Among the various research groups involved in this issue, Zhang et al. showed that the effect of nanoscale carborane ruthenium (II)-arene complexes, showed significant results in treating lung cancer.[45] The authors suggest that this complex containing $\mathrm{Ru}(\mathrm{II})$ may be a strong candidate for lung cancer chemotherapy. The results provide evidence that tumor growth can be inhibited by anti-cancer ruthenium (II) arene complex in vivo. Clearly, a better understanding of the mechanism of action and possible chemotherapeutic activity of the complex of $\mathrm{Ru}(\mathrm{II})$-arene could certainly benefit the future clinical treatment of this cancer.

Although one may propose alternatives of the possible reaction mechanisms between the monomers: the trans-[ $\left.\mathrm{RuCl}_{2}(\mathrm{vpy})_{4}\right]$ complex, styrene, divinylbenzene and 4-vinylpyridine, it is not possible to safely affirm what structures will be formed by a combination of these monomers (Figure 2). However, the authors suggest that the formation of crosslinking between the complex combination with the monomers participating in the structure (Figure 3 ) is highly probable, where the polymerization and the polymeric chain propagation could occur in both, by double bond cleavage of the ligands of the metal complex (vpy) and the interpolation of the monomers (sty, DVB, vpy) among themselves. Thus, there is still no concrete answer on the exact formulation of co- and terpolymers synthesized. Efforts in this direction have been intensified by several researchers in order to have an idea of the structural composition of these polymers and how, or even if, these bonds significantly influence the formation of these new functional polymers nanocomposites.

In this chapter we plan on reviewing various nanocomposites using a polymer-based matrix with transition metal complexes and a wide range of inorganic nanoparticles with varying optical, antiseptic and magnetic properties, namely $\mathrm{ZnO}$ nanoparticles which have interesting optical properties; silver nanoparticles (AgNPs) which have antimicrobial properties as well as known optical properties and magnetic nanoparticles ( $\left.\mathrm{CoPt}_{3}\right)$ which have well-defined magnetic properties.

\section{Inorganic nanoparticle incorporation}

The incorporation of nanoparticles as a filler in polymer matrices is interesting mainly due to the different properties resulting therefrom and compared to their bulk analogues. 

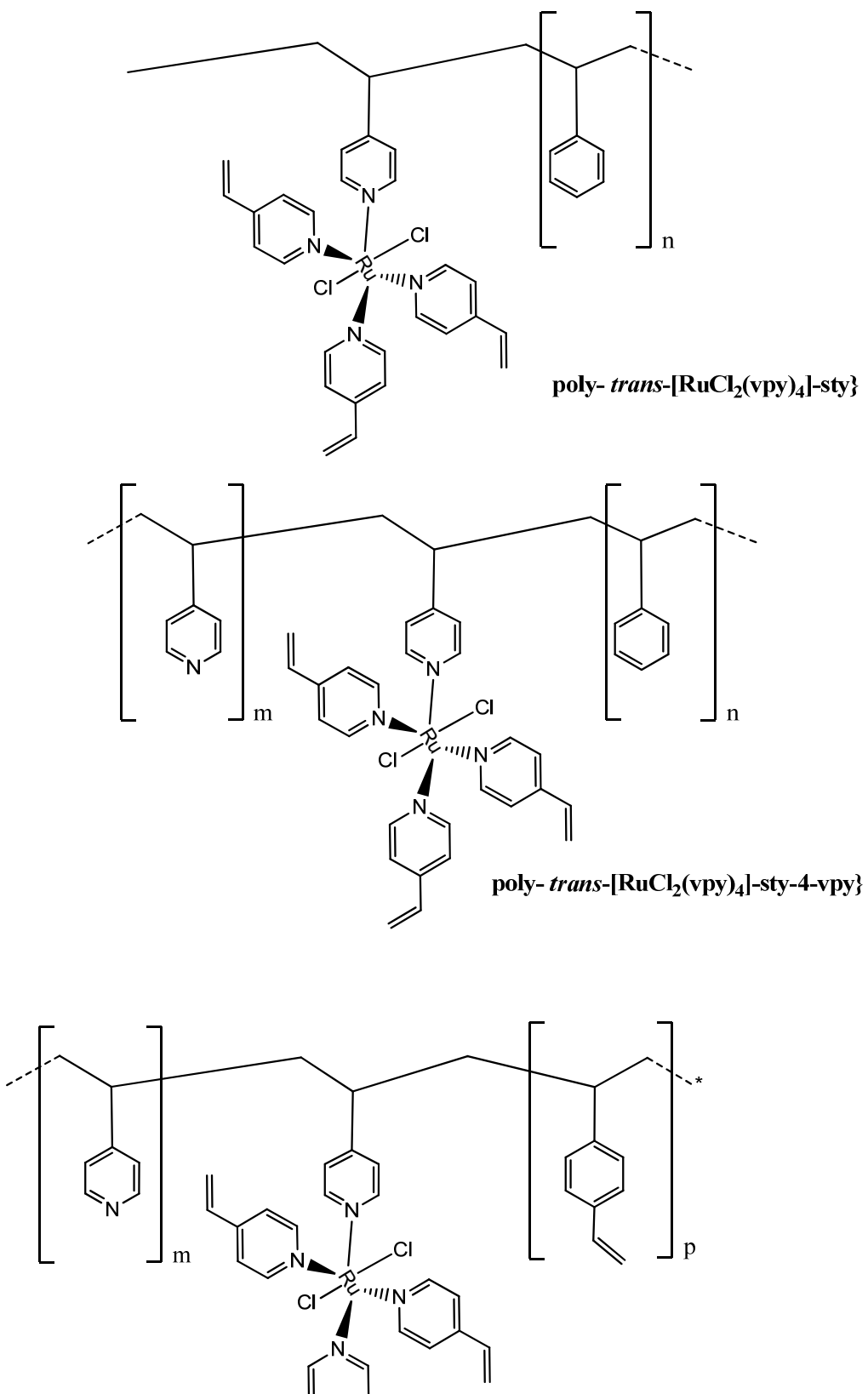

poly- trans-[RuCl $\left.\mathbf{R}_{2}\left(\mathrm{vpy}_{4}\right]_{-}-4-\mathrm{vpy}-\mathrm{DVB}\right\}$

Figure 3. Proposed polymeric structure containing monomers: styrene, divinylbenzene, 4-vinylbenzene and ruthenium complex. 
Several authors have described changes in optical, electrical and mechanical properties when the size of a certain material reduces to nanoscale dimensions.[46, 47] This type of interaction can influence the molecular dynamics of a polymer hence resulting in significant changes in their physical, thermal behavior and mechanical properties. Bullions et al. investigated a hybrid material consisting of NPs embedded in $\mathrm{SiO}_{2}$ poly(imide).[48] The authors concluded that the formation of chemical bonds between the NPs and certain terminal groups of poly(imide), confines the space accessible to the polymer chains in the molecular dynamics influencing polymer, which can result in changes in thermal stability and consequently its glass transition temperature. A controlled polymer synthesis in the presence of inorganic NPs, allows rigorous control over the matrix's physical/chemical properties. Nonetheless, the chemical affinity between nanoparticles and polymer is a major aspect in nanocomposite preparation. The compatibility of the inorganic material with the polymer matrix can be improved through the chemical surface modification of the particles. At times, surface modification may be necessary to promote chemical compatibility between components. For example, in the case of trioctylphosphine oxide (TOPO)-prepared semiconductor nanoparticles, these can be used directly in the synthesis of an organic matrix-based nanocomposite, once these are passivated with molecules of hydrophilic nature.

For the preparation of nanocomposites there is a diversity of polymer synthesis techniques, the most common being: dispersion polymerization, mass polymerization and emulsion polymerization. Recently the development of new radical polymerization methods, currently denominated by controlled/"living" polymerization, came to ease new methodologies that are prepared in a controlled manner.[18] This method was used for various inorganic materials, such as $\mathrm{TiO}_{2}$ [49-51] and $\mathrm{SiO}_{2}$,[52] where these were directly dispersed in the monomer. More recently the NP encapsulation by an in situ miniemulsion polymerization was demonstrated with poly-styrene,[53-55] poly-butyl acrylate[53,56] and a poly-styrene poly-methylmetacrylate copolymer.[57] However changes in the crystallization of semicrystalline polymer matrices in nanocomposites has also been described.[58] For example, a significant influence of NPs morphology on the crystallization kinetics of polyamide in a hybrid material consisting of an array of poly(tetramethylene terephthalamide) fibers or containing $\mathrm{SiO}_{2}$ spheres with nanometric dimensions.[59] When preparing $\mathrm{Bi}_{2} \mathrm{~S}_{3} / \mathrm{Nylon}$ nanocomposites, the authors found that the $\mathrm{Bi}_{2} \mathrm{~S}_{3}$ nanofibers act as nucleation sites, resulting in a larger number of spherulites in the nanocomposite when compared to the pure polymer.

Depending on the envisioned application, various types of fillers may be used for loading the nanocomposite which may differ, for example, their morphological or other properties, such as heat resistance or chemical reactivity. Studies have shown that for the incorporation of metal and semiconductor NPs in this polymeric matrix, these nanoparticles can be dispersed among the crosslinking of the polymeric matrix, as shown in the Figure 4 . Amongst the most common fillers for polymer-based nanocomposites are carbonates, sulfates, alumino-silicates and metal oxides $\left(\mathrm{Al}_{2} \mathrm{O}_{3}, \mathrm{Fe}_{2} \mathrm{O}_{3}, \mathrm{ZnO}\right)$.[60] Semiconductor NPs such as CdS, ZnS, or CdSe have also been widely used due to their optical properties.[61, 62] Some of the examples of inorganic particles cited in the literature are the use of $\mathrm{TiO}_{2} \mathrm{NPs}$ in 


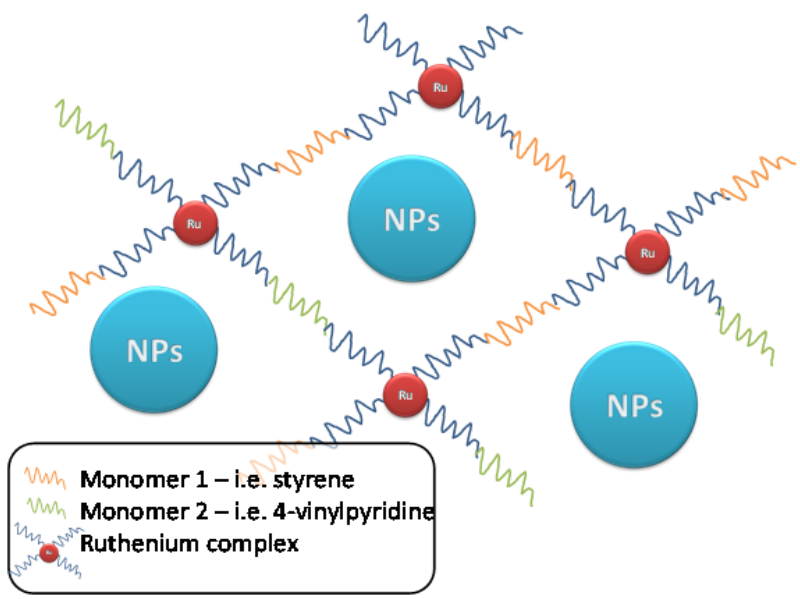

Figure 4. Proposed crosslinked structure of prepared metallpolymers nanocomposite.

the preparation of composites for paints and coatings[46, 63] and $\mathrm{SiO}_{2} \mathrm{NPs}$, which can give added strength or flame retardant characteristics to nanocomposites.[64, 65]

\section{Ruthenium complex based copolymers with incorporated inorganic nanoparticles}

The following section summarizes relevant properties of functional ruthenium based nanocomposites when doped with diverse inorganic nanoparticles (magnetic, antimicrobial and luminescent nanoparticles).

\subsection{ZnO NP doped Ru complex/styrene copolymer}

Semiconductor NPs show size-dependent optical properties and have been widely explored as new optical materials.[47] New optically active inorganic/polymer nanocomposite have been prepared when using semiconductor NPs together with polymers. As with all nanocomposites the intrinsic properties of the starting materials maintain but new properties due to synergistic effects arising from the combination of the inorganic and organic components may arise.[66] The homogeneous distribution of inorganic NPs within the polymer matrix and the strong interface adhesion between the matrix and nano-fillers are important aspects to be considered because of their influence in the nanocomposites' performance.[67] Segala et al. reported the preparation of nanocomposites containing ZnO NPs dispersed in the co-polymer poly-\{trans-[ $\left.\left.\mathrm{RuCl}_{2}(\mathrm{vpy})_{4}\right]-\mathrm{sty}\right\}$.[68] The polymer was prepared through reaction of the complex trans-[ $\left.\mathrm{RuCl}_{2}(\mathrm{vpy})_{4}\right]$ with styrene.[69]

The ZnO NPs were previously prepared and their optical properties monitored by UVvisible spectrocsopy and size through high resolution transmission electron microscopy (HR-TEM) (Figure 5). A quantum mechanical effect occurring in the semiconductor NPs is the increase in band gap, with the reduction in particle size. The quantum confinement 
effect is clearly seen in Figure 5 inset. The literature shows that bulk $\mathrm{ZnO}$ exhibit a band gap of $3.37 \mathrm{eV}$ (or about $368 \mathrm{~nm}$ ), whereas the NPs band gap has a characteristic optical feature at $357 \mathrm{~nm}$. Theoretical calculations based on the effective mass approximation for spherical particles[70, 71] provides a size estimate of $5.2 \mathrm{~nm}$ diameter of the ZnO NPs. The size of the NPs was confirmed through HR-TEM in which the approximate size is in the order of $5 \mathrm{~nm}$.
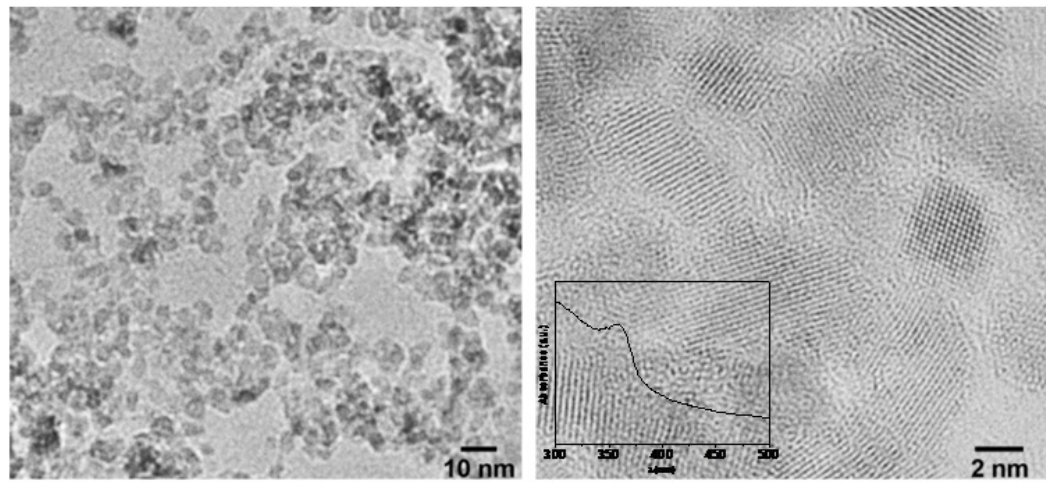

Figure 5. HR-TEM images of ZnO NPs used in the preparation of the nanocomposite. Inset: Optical spectrum of coloidal suspension of ZnO NPs.

When incorporating the semiconductor NPs into the copolymer matrix, the properties of the initial NPs were maintained, such as optical and structural properties.[68] Scanning electron microscopy (SEM) of the nanocomposite and energy-dispersive $\mathrm{X}$-ray spectroscopy (EDS), clearly demonstrate the homogeneous presence of $\mathrm{Zn}$ and $\mathrm{Ru}$ throughout the whole sample. (Figure 6).

Nanocomposites containing $\mathrm{ZnO}$ and poly-\{trans-[ $\left.\mathrm{RuCl}_{2}(\mathrm{vpy})_{4}\right]$-sty $\}$ have been prepared and the results point to a homogeneous nanocomposite.[68] This study allows further development of this synthetic strategy to obtain homogeneous nanocomposites of variable composition that can find practical interest in ruthenium-based sensor devices.
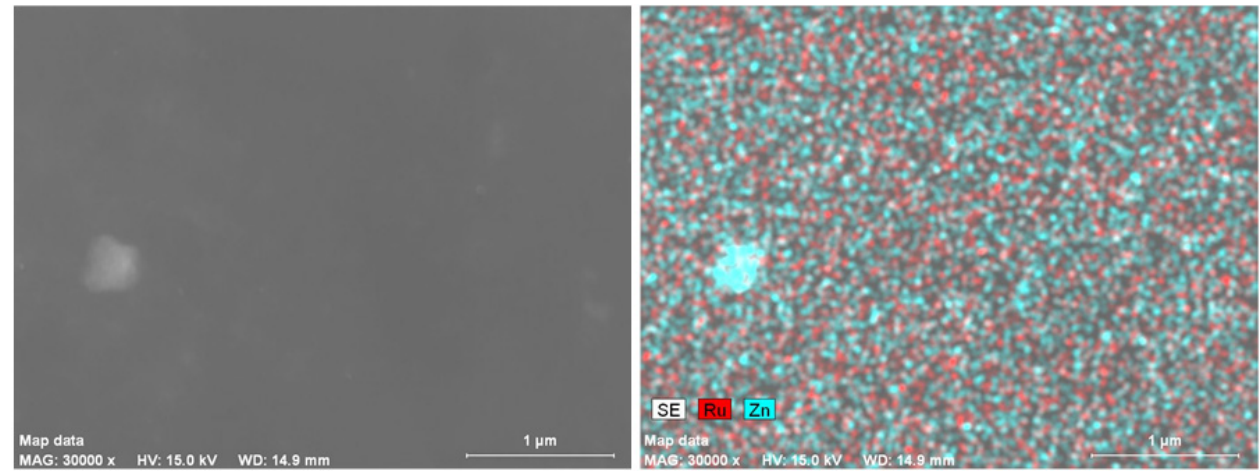

Figure 6. SEM image and EDS mapping of ZnO NPs dispersed in the co-polymer poly-\{trans[ $\mathrm{RuCl}_{2}$ (vpy)4]-sty\} 


\subsection{Ag NP doped Ru complex/styrene/divinylbenzene copolymer}

The bactericidal effects of ionic silver are well-known and have been used since ancient times. The precious metal was originally used as an effective antimicrobial agent and is relatively free of side effects. However, with the development of modern antibiotics to treat infectious disease, the use of silver in the clinical setting has been limited predominantly to topical cream based silver sulfadiazine to prevent infections associated with treatment of burns.[72-74] However recent studies revealed that Ag NPs have improved antibacterial properties when compared with bulk silver and that even nanomolar concentrations of Ag NPs can be more effective than micromolar concentrations of silver ions,[75] thus leading to an increased interest on materials containing nano-silver. Silver ions are known to be extremely reactive and could readily bind with an assortment of negatively charged molecules such as inorganic anions, proteins, RNA and DNA. Consequently, the antibacterial property of silver ions has been credited to its interaction with thiols, along with other groups such as carboxylates, phosphates, hydroxyls, imidazoles, indoles and amines. Roe and coworkers developed a method to coat plastic catheters with bioactive Ag NPs. The catheters are non-toxic devices capable of targeted and sustained release of bactericidal silver at the implantation site and were useful in preventing infectious complications in patients.[76] Bowler et al. assessed the antimicrobial properties of an absorbent topical wound dressing containing ionic silver, samples were tested with a diversity of known burn wound pathogens in a simulated wound fluid model. and verified that the silvercontaining dressing is likely to provide a barrier to infection in controlling partialthickness burns.[72] A relevant factor in the evaluation of biocide action of different materials is their behavior against the bactericidal dose-dependent effect on the different strains of bacteria. Because of the complexity in determining the actual bioavailability of $\mathrm{Ag}$, values of minimum inhibitory concentration of about 100 strains of Staphylococcus aureus was reported, with a range $8-80 \mathrm{mg} / \mathrm{L}$ when using $\mathrm{AgNO}_{3}$.[77] Similarly, minimum inhibitory concentration values for Ag studied with approximately 100 strains of Pseudomonas aeruginosa showed a range of 8 to $70 \mathrm{mg} / \mathrm{L}$. These studies showed that some strains are resistant to $\mathrm{Ag}$, and in fact, resistant strains of bacteria were isolated more than 70 years ago and its mechanism of resistance to Ag has been investigated.[77, 78]

Dutra et al. reported the preparation and characterization of the nanocomposite between a poly-\{trans-[ $\mathrm{RuCl}_{2}$ (vpy) 4 -styrene-divinylbenzene\} or styrene-divinylbenzene-4vinylpiridine matrix containing Ag NPs.[79] Non-aqueous polymerization using benzoyl peroxide as the initiator was the method used to prepare these materials. The Ag NPs were obtained through the chemical reduction using $\mathrm{NaBH}_{4}$ as reducing agent and sodium citrate as stabilizer.[80] The Ag NPs optical properties were monitored by UVvisible spectroscopy and size and morphology confirmed through TEM. The nanocomposites morphology was characterized by Field Emission Gun Scanning Electron Microscope (FEG-SEM) and the thermal properties were studied. 

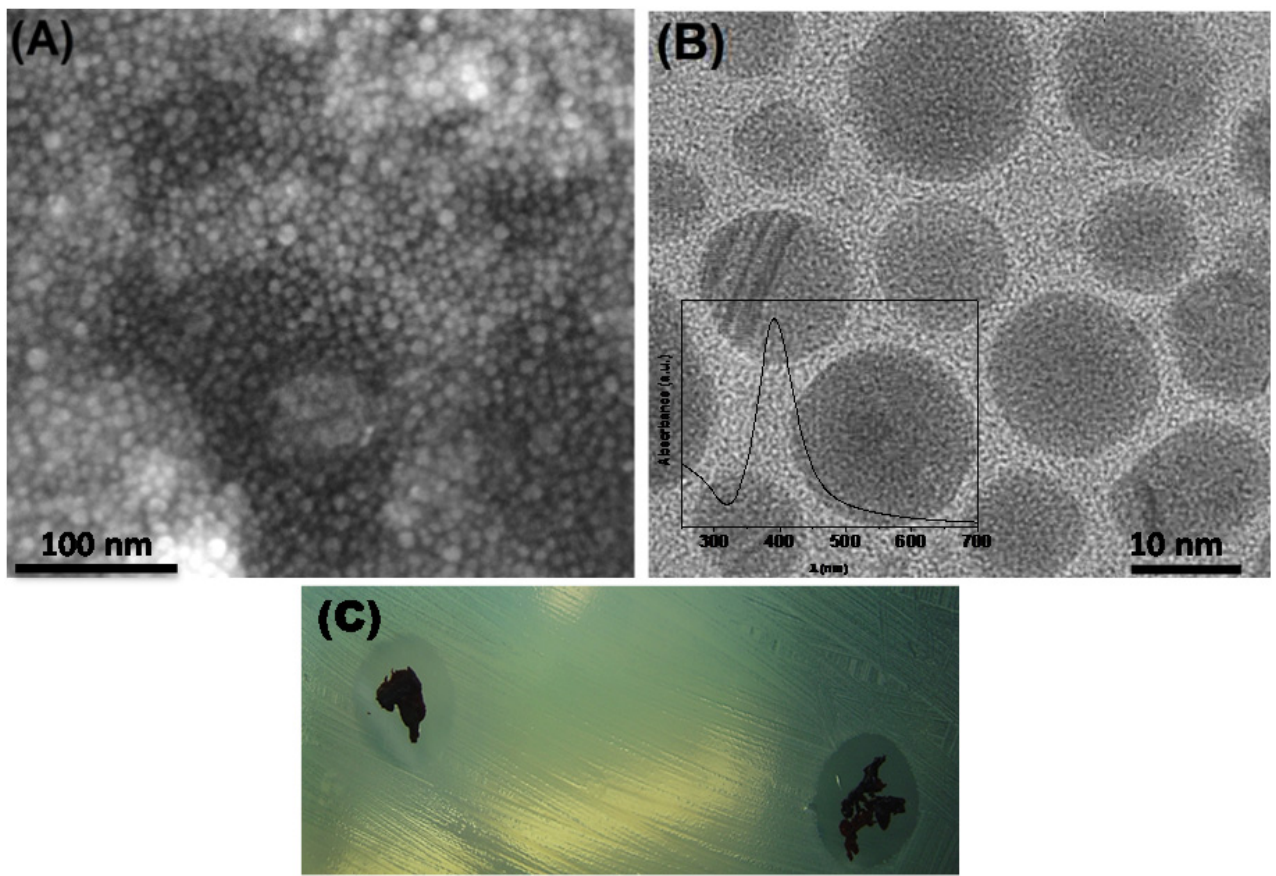

Figure 7. a) FEG-SEM image and b) HR-TEM image of silver nanoparticles. Inset: optical spectrum of AgNPs and c) Photograph of microculture plate containing the microorganism Staphylococcus aureus in the presence of poly-\{trans-[ $\left.\mathrm{RuCl}_{2}(\mathrm{vpy})_{4}\right]$-styrene-divinylbenzene\}/AgNPs nanocomposite.

The antimicrobial action of the nanocomposite was evaluated using various microorganisms: Staphylococcus aureus and Escherichia coli and was confirmed by the presence of an inhibition halo of the bacterial growth in seeded culture media (Figure 7c). This growth inhibition caused by the presence of silver nanoparticles in the polymer reveals the antiseptic properties of the material. Authors suggested that the absence of ruthenium complex in the polymeric matrix interfered with the release of silver ions into the media, not conferring this material antimicrobial activity. The antimicrobial activity of the silver in the polymeric matrix can also be important for the prevention of proliferation of adherent bacteria in the surface of the polymeric materials, increasing like this the materials' lifetime. Polymeric matrix impregnated with Ag NPs ensures new surface properties that perform in the prevention of microorganism's adherence on the surface and deposits of proteins.

\subsection{Magnetic NP doped Ru complex/styrene/divinylbenzene copolymer}

Magnetic NPs are of great interest to researchers and cover a wide subject area, including magnetic fluids, catalysts, biotechnology, magnetic resonance imaging, prevention of the environment, among others.[81] Although a reasonable amount of methods have been developed for the synthesis of magnetic NPs with a wide variety of different compositions, the successful application of these magnetic NPs depend on their stability under different 
conditions. In most applications, the particles properties are enhanced when present in the 10-20 $\mathrm{nm}$ size range. However, depending on the application, an inevitable problem associated with the particle size is its intrinsic instability over time has to be regarded. Some smaller particles tend to form agglomerates to reduce the energy associated with large surface area relative to the volume of nanometric particles. For most applications it is crucial to develop strategies to protect the chemical stability of the NPs in relation to the magnetic degradation during and after the synthesis. These strategies include coating with organic species, including surfactants or polymers, or a coating with an inorganic layer such as silica or carbon. It is notable that in many cases, protection of the particles or coating not only stabilizes NPs, but may also be used for additional functionality, for example, with NP or other ligands, depending on the desired application.[81] Several syntheses of Fe, Co, FePt and $\mathrm{Fe}_{x} \mathrm{Co}_{y} \mathrm{Pt}_{100-x-y} \mathrm{NPs}$ have recently been developed to produce particles of controlled size and narrow size distributions. They are currently the focus of scientific research aimed at understanding the formation mechanism of monodisperse NPs and the influence of size and shape in their magnetic behaviour.[82] The literature reports the preparation of polydisperse $2 \mathrm{~nm}$-sized alloy of Co-Pt prepared from organometallic precursors in the presence of a polymer.[83-85]

On the other hand, researchers at Ohio State University reported the development of magnetic NPs that promises rapid detection and elimination of the bacteria Escherichia coli (E.coli), anthrax (Bacillus anthracis) and other bacteria harmful to human health.[86] These studies have demonstrated the potential of the magnetic NPs studied and their aid in the rapid detection of E.coli strains in approximately five minutes, and removing $88 \%$ of the bacteria by providing a very attractive field for the decontamination of pathogenic microbes and diagnostic applications.[86] These studies were pioneers in using magnetic NPs to detect, quantify and differentiate E.coli cells.

A promising application of magnetic NPs is as drug carriers as well as in drug release, initially proposed by Widder et al. in the 70's.[87] The magnetic drug carriers have the potential to carry a large amount of drug to a certain body part, thus avoiding toxicity and adverse effects of excessive use of a large dose of drugs in the body. Although to date, there has been a breakthrough in in vivo applications, clinical studies in real situations are still problematic. Many fundamental issues in systems for controlled drug release need to be resolved, such as size-controlled synthesis and stability of the magnetic NPs, the biocompatibility of the coating layers (polymer or silica), links between drug-particle, among other physiological parameters.[81]

The literature describes various synthesis methods of interest to develop new bio-magnetic nanocomposite applications.[56, 88] However, some of these proposed methods suggest a post-synthetic step in order to prevent the liberation of the magnetic NPs. To investigate this authors have proposed an in situ synthetic method to incorporate the magnetic NPs during the synthesis of the nanocomposite. This section will present some results obtained in the preparation and characterization of magnetic CoPt 3 NPs and in situ incorporation of these particles in the poly-\{trans-[ $\left.\left.\mathrm{RuCl}_{2}(\mathrm{vpy})_{4}\right]-\mathrm{sty}\right\}$ polymer matrix. Although these 
nanocomposites are not to be directly applied in Nanomedicine they may provide useful clues in the formulation of other materials.

The magnetic CoPt3 NPs were characterized by UV-vis spectroscopy (Figure 8-inset).The optical spectrum of the magnetic NPs presents two characteristic bands, at $319 \mathrm{~nm}$ and 407 $\mathrm{nm}$. The observation of the UV/vis spectra obtained from the starting materials, ie, salts of Co (II) and Pt (VI) in ethylene glycol showed an intense band at $522 \mathrm{~nm}$ for the Co (II) and two minor bands intensity for Pt (VI), $363 \mathrm{~nm}$ and $458 \mathrm{~nm}$. However, the optical spectrum obtained for this alloy shows distinct bands of the starting materials, which indicates the presence of magnetic material, CoPt3.[82] The morphology of the CoPt3 NPs was analyzed by SEM and EDX confirmed the presence of metals in the magnetic alloy, and its respective mean ratio, Co:Pt, 1:3 (Figure 8). The presence of spherical agglomerates was observed by coalescence of smaller particles. However, the nanoscale of the CoPt3 NPs was confirmed by TEM. Figure 8(right) shows TEM images obtained from a sample of these magnetic particles.
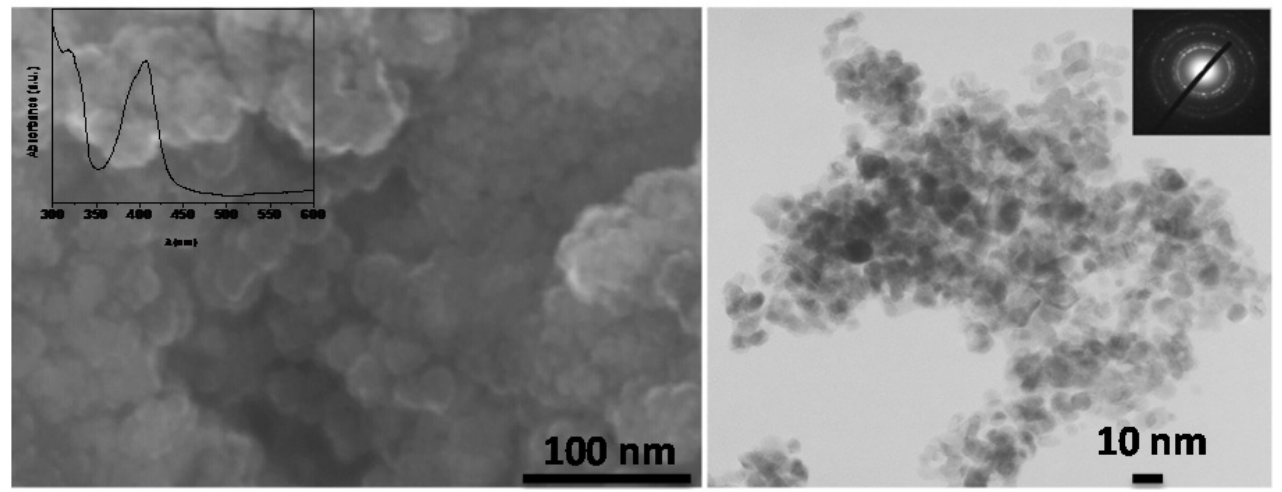

Figure 8. SEM image (left) with inset optical spectrum and TEM image (right) of CoPt3 NPs.

The nanocomposite CoPt $3 /$ poly-\{trans-[ $\left[\mathrm{RuCl}_{2}(\mathrm{vpy})_{4}\right]$-sty\} was synthesized using the in situ method with a nominal percentage of $0.5 \%(\mathrm{w} / \mathrm{w}) \mathrm{CoPt}_{3}$ in relation with the styrene monomer and the complex trans-[ $\left.\mathrm{RuCl}_{2}(\mathrm{vpy})_{4}\right]$-sty] and characterized by UV-vis spectroscopy. The optical spectrum of the magnetic nanocomposite present bands in the region of 320 to $410 \mathrm{~nm}$ (Figure 9b). A shoulder and band broadening observed in the 450 $\mathrm{nm}$ region of the optical spectrum, may suggest the overlap of the bands that characterize the complex trans-[ $\left.\mathrm{RuCl}_{2}(\mathrm{vpy})_{4}\right]$ with the magnetic NPs characteristic band. The morphology of the magnetic nanocomposite was analyzed simultaneously by SEM and TEM and the presence of the nanoparticles homogeneously dispersed in the polymeric matrix was observed. However, there are dots and small beads over the whole surface of the nanocomposite examined by SEM, suggesting an agglomeration of magnetic NPs incorporated in the copolymer matrix. The average size of the NPs is in the $10 \mathrm{~nm}$ range, showing that the average size of NP was not significantly altered during the synthesis of the nanocomposite. Larger particles are probably caused by coalescence of smaller particles. 
EDX mapping was made on the SEM image of the nanocomposite and showed the homogenous presence of the $\mathrm{CoPt}_{3}$ alloy over the entire surface of the polymer matrix.
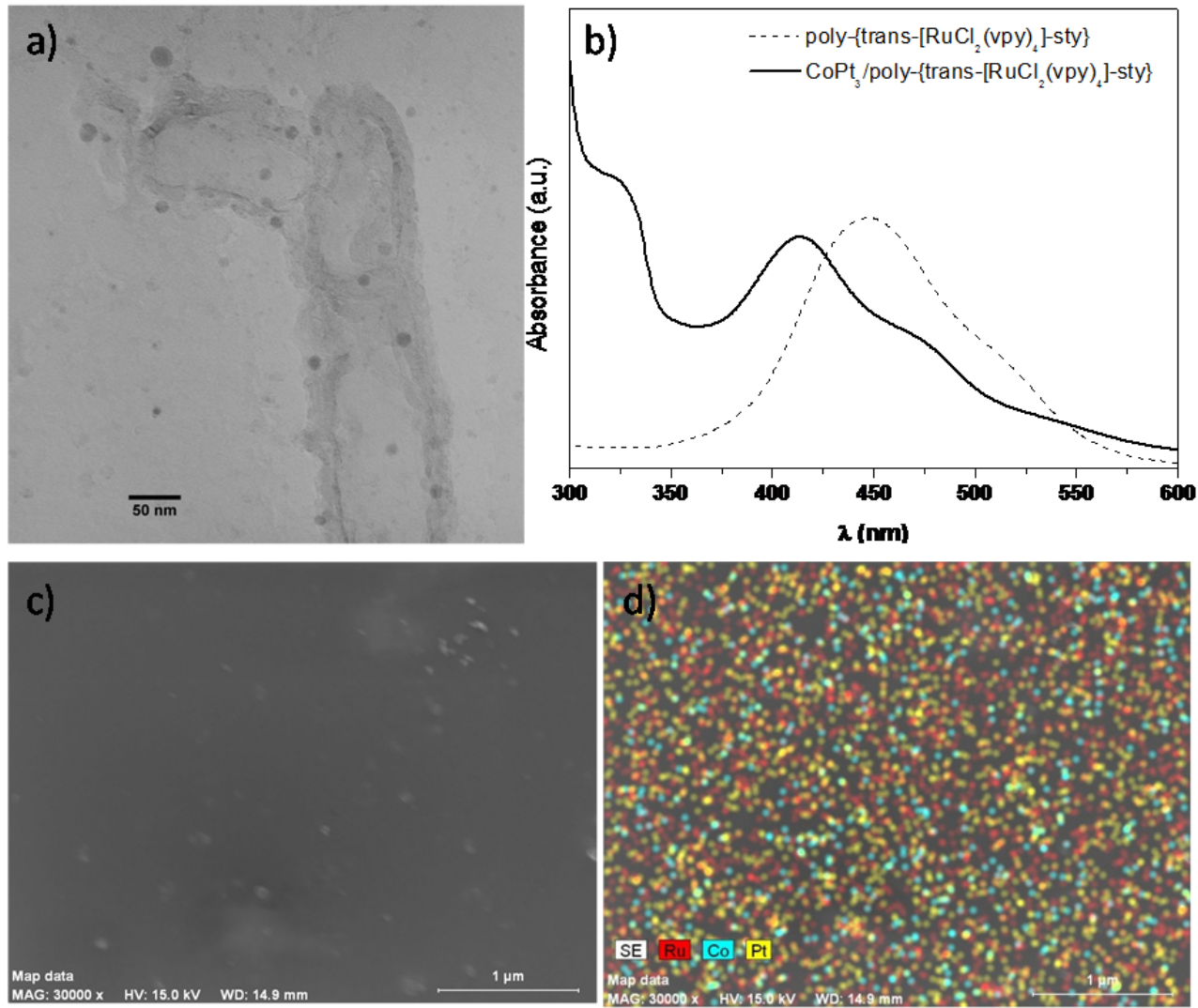

Figure 9. a) TEM image; b) optical spectra; c) SEM image and d) EDS mapping of the nanocomposite $\mathrm{CoPt}_{3} /$ poly-\{trans- $\left[\mathrm{RuCl}_{2}(\mathrm{vpy})_{4}\right]$-sty\} $0.5 \%$.

\section{Concluding remarks and future trends}

In this chapter we have discussed studies involving nanocomposites prepared from the complex trans-[ $\left.\mathrm{RuCl}_{2}(\mathrm{vpy})_{4}\right]$, with the monomers styrene, divinylbenzene and 4vinylpyridine, with the incorporation of functional nanoparticles. To each type of nanoparticles, different properties may be attributed: (1) antimicrobial properties in the presence of Ag NPs, (2) luminescent properties in the presence of $\mathrm{ZnO}$ NPs and (3) magnetic properties of the alloy in the presence of CoPt3. The Ag NPs precursors of antibacterial nanocomposites were prepared and characterized. The synthesis of the copolymers were carried out in these emulsions in the presence of complex trans$\left[\mathrm{RuCl}_{2}(\mathrm{vpy})_{4}\right]$ monomer and other monomers such sty, DVB and vpy, which will form the polymeric matrices. These nanocomposites were characterized by optical, structural and 
morphological techniques through UV-visible spectroscopy, SEM and TEM analysis. The antiseptic property of these new nanocomposite materials was confirmed by microbiological testing using the Gram-positive, S. aureus (ATCC-25923) and Gram-negative, E. coli (ATCC-25922) for Ag NPs impregnated with the polymer. The nanocomposites containing $\mathrm{ZnO}$ NPs with luminescent properties incorporated in the copolymers poly\{trans-[ $\mathrm{RuCl}_{2}$ (vpy) 4 -sty showed that the synthesis method using in situ promotes better dispersion and a better distribution of the ZnO NPs along the polymeric matrix compared with the nanocomposite prepared by the analogous ex situ method. ZnO/poly-\{trans$\left[\mathrm{RuCl}_{2}(\mathrm{vpy})_{4}\right]$-sty\}nanocomposites prepared were fully characterized at the optical, structural and morphological level, through the techniques of UV-vis spectroscopy, analysis by SEM and TEM. CoPt 3 NPs, with superparamagnetic properties, were incorporated into a magnetic poly-\{trans-[ $\left.\mathrm{RuCl}_{2}(\mathrm{vpy})_{4}\right]-$ sty $\}$ nanocomposite prepared and characterized. TEM images show that $\mathrm{CoPt}_{3}$ NPs remained unchanged and are homogeneously embedded through the polymeric matrix of the magnetic nanocomposite The development of highly technological materials with antiseptic, optical and magnetic properties present in ruthenium complexes with biological activity are promising therapeutic applications with a high possibility of success if applied in the medical field and a variety of technological applications.

\section{Author details}

\section{Karen Segala}

Department of Bioprocesses and Materials Engineering (DEMBio), State University of Campinas, UNICAMP, Brazil

Angela S. Pereira

CICECO, University of Aveiro, Portugal

\section{Acknowledgement}

K.S. is so grateful to CNPq and Capes (PNPD 02625/09-1-linha MEC/CAPES) for financially supporting this project and for the research (post-doctoral fellowship), Faculdade de Engenharia Química, FEQ/UNICAMP, Brasil, and LNLS/LNNano (Brazilian Synchrotron Light Laboratory) for HR-TEM and SEM/FEG images. A.S.P acknowledges Fundação para a Ciência e Tecnologia for her post-doctoral fellowship (SFRH/BPD/44398/2008). The authors would also like to acknowledge the financial support from the Universidade de Aveiro and FCT (PTDC/EQU-EQU/098617/2008).

\section{References}

[1] Hezinger AFE, Tessmar J, and Gopferich A, (2008)Polymer coating of quantum dots - A powerful tool toward diagnostics and sensorics. Eur. J. Pharm. Biopharm. 68: p. 138.

[2] Jorge P, Martins MA, Trindade T, Santos JL, and Farahi F, (2007)Optical fiber sensing using quantum dots. Sensors. 7: p. 3489. 
[3] Gao XH, Cui YY, Levenson RM, Chung LWK, and Nie SM, (2004)In vivo cancer targeting and imaging with semiconductor quantum dots. Nat. Biotechnol. 22(8): p. 969.

[4] Pellegrino T, Manna L, Kudera S, Liedl T, Koktysh D, Rogach AL, Keller S, Radler J, Natile G, and Parak WJ, (2004)Hydrophobic nanocrystals coated with an amphiphilic polymer shell: A general route to water soluble nanocrystals. Nano Lett. 4(4): p. 703.

[5] Carion O, Mahler B, Pons T, and Dubertret B, (2007)Synthesis, encapsulation, purification and coupling of single quantum dots in phospholipid micelles for their use in cellular and in vivo imaging. Nat. Protoc. 2: p. 2383.

[6] Dubertret B, Skourides P, Norris DJ, Noireaux V, Brivanlou AH, and Libchaber A, (2002)In vivo imaging of quantum dots encapsulated in phospholipid micelles. Science. 298(5599): p. 1759.

[7] Liu SW, Lee CM, Wang SN, and Lu DR, (2006)A new bioimaging carrier for fluorescent quantum dots: Phospholipid nanoemulsion mimicking natural lipoprotein core. Drug Delivery. 13(2): p. 159.

[8] Struck M and Widdecke H, (1996)Surface functionalization of polymer networks: Sulfonation of the internal surface of macroporous styrene-divinylbenzene copolymers. Angew. Makromol. Chem. 235: p. 131.

[9] Williams KA, Boydston AJ, and Bielawski CW, (2007)Main-chain organometallic polymers: synthetic strategies, applications, and perspectives. Chem. Soc. Rev. 36(5): p. 729.

[10] Schubert US and Eschbaumer C, (2002)Macromolecules containing bipyridine and terpyridine metal complexes: towards metallosupramolecular polymers. Angew. Chem., Int. Ed. Engl. 41(16): p. 2892.

[11] Abd-El-Aziz AS, Shipman PO, Boden BN, and McNeil WS, (2010) Synthetic methodologies and properties of organometallic and coordination macromolecules. Prog. Polym. Sci. 35(6): p. 714.

[12] Maria L, Leite M, Costa MAS, Ribeiro JMS, Senna LF, and Silva MR, (2004)Characterization of magnetic microspheres based on network styrene and divinylbenzene copolymers. Mater. Lett. 58(24): p. 3001.

[13] Mahdavian AR and Khoee S, (2002)A facile and efficient method for preparation of chiral supported poly(styrene-divinylbenzene) copolymers. React. Funct. Polym. 50(3): p. 217.

[14] Leon-Gonzalez ME and Perez-Arribas LV, (2000)Chemically modified polymeric sorbents for sample preconcentration. J. Chromatogr., A. 902(1): p. 3.

[15] de Oliveira AJB, de Aguiar AP, de Aguiar M, and Maria LCD, (2005)How to maintain the morphology of styrene-divinylbenzene copolymer beads during the sulfonation reaction. Mater. Lett. 59(8-9): p. 1089.

[16] Franco CV, Marques da Silva Paula M, Goulart G, de Lima LFCP, Noda LK, and Gonçalves NS, (2006)Thermal analysis, Raman spectroscopy and scanning electron microscopy of new polymeric material containing in-chain ruthenium complex: Poly- 
\{trans-[ $\left.\left[\mathrm{RuCl}_{2}(\mathrm{vpy})_{4}\right]-\mathrm{co}-\mathrm{styrene}\right\}$ and poly-\{trans-[ $\left.\mathrm{RuCl}_{2}(\mathrm{vpy})_{4}\right]-4$ vinylpyridine-styrene\}. Mater. Lett. 60(21-22): p. 2549.

[17] Kelch S and Rehahn M, (1999)Synthesis and properties in solution of rodlike, 2,2':6',2"terpyridine-based ruthenium(II) coordination polymers. Macromolecules. 32(18): p. 5818.

[18] Asua JM, (2002)Miniemulsion polymerization. Prog. Polym. Sci. 27(7): p. 1283.

[19] Friese VA and Kurth DG, (2009)From coordination complexes to coordination polymers through self-assembly. Current Opinion in Colloid \&amp; Interface Science. 14(2): p. 81.

[20] Islam A, Singh SP, and Han L, (2011)Synthesis and Application of New Ruthenium Complexes Containing $\beta$-Diketonato Ligands as Sensitizers for Nanocrystalline $\mathrm{TiO}_{2}$ Solar Cells. International Journal of Photoenergy. 2011.

[21] Moucheron C, (2009)From cisplatin to photoreactive Ru complexes: targeting DNA for biomedical applications. New J. Chem. 33(2): p. 235.

[22] Abel EW, Bennett MA, and Wilkinson G, (1959)Norbornadiene-metal complexes and some related compounds. J. Chem. Soc. p. 3178.

[23] Lewis J, Mabbs FE, and Walton RA, (1967)The preparation, infrared spectra, and magnetic properties of some ruthenium(II), ruthenium(III), and osmium(III) complexes. J. Chem. Soc. A. p. 1366.

[24] Gilbert JD, Rose D, and Wilkinson G, (1970)Preparative use of blue solutions of ruthenium(II): ruthenium-(II) and -(III) complexes with amines, nitriles, phosphines, etc. J. Chem. Soc. A. p. 2765.

[25] Lewis J, Mabbs FE, and Walton RA, (1967)The preparation, infrared spectra, and magnetic properties of some ruthenium(II), ruthenium(III), and osmium(III) complexes. J. Chem. Soc. A.

[26] Sugahara E, Paula MMS, Vencato I, and Franco CV, (1996)Synthesis, crystal structure and properties of tetranuclear copper(I) complex containing 3-(pyrrol-1ylmethyl)pyridine as ligand. J. Coord. Chem. 39(1): p. 59.

[27] Paula MMS and Franco CV, (1996)Synthesis, properties and an electroactive film of ruthenium(II) complexes with the pyridine derivative ligand: trans- $\mathrm{RuCl}_{2}(\mathrm{pmp})_{4}$ center $\operatorname{dot}(\mathrm{pmp}=3-($ pyrrol-1-ylmethyl)pyridine). J. Coord. Chem. 40(1-2): p. 71.

[28] Franco CV, Prates PB, deMoraes VN, and Paula MMS, (1997)Oxidative formation of electroactive film from polypyridinyl complexes of ruthenium(II)-containing 3-(pyrrol1-ylmethyl)pyridine. Synth. Met. 90(2): p. 81.

[29] Paula MMS and Franco CV, (1995)Electrochemical studies of the bimetallic complex formed by ruthenium(II) polypyridine and manganese(III) porphyrin. J. Coord. Chem. 36(3): p. 247.

[30] Fricker SP, Slade E, Powell NA, Vaughan OJ, Henderson GR, Murrer BA, Megson IL, Bisland SK, and Flitney FW, (1997)Ruthenium complexes as nitric oxide scavengers: a potential therapeutic approach to nitric oxide-mediated diseases. Br. J. Pharmacol. 122(7): p. 1441. 
[31] Paula MMS, de Moraes VN, Mocellin F, and Franco CV, (1998)Electroreductive deposition of polymeric coatings having Ru-II redox centers on $\mathrm{Pt}, \mathrm{Pd}$ and sintered Fe(5-10)\%Ni electrodes. J. Mater. Chem. 8(9): p. 2049.

[32] Calvert JM, Schmehl RH, Sullivan BP, Facci JS, Meyer TJ, and Murray RW, (1983)Synthetic and mechanistic investigations of the reductive electrochemical polymerization of vinyl-containing complexes of iron(II), ruthenium(II), and osmium(II). Inorg. Chem. 22(15): p. 2151.

[33] Denisevich P, Abruna HD, Leidner CR, Meyer TJ, and Murray RW, (1982)Electropolymerization of vinylpyridine and vinylbipyridine complexes of iron and ruthenium - homopolymers, copolymers, reactive polymers. Inorg. Chem. 21(6): p. 2153.

[34] Bandeira MCE, Prochnow FD, Costa I, and Franco CV, Corrosion characterization of electrodeposited organometallic films on $\mathrm{Nd}-\mathrm{Fe}-\mathrm{B}$ permanent magnets, in Advanced Powder Technology II, L. Salgado, F.A. Filho, and R. Muccilo, Editors. 2001. p. 673.

[35] Bandeira MCE, Prochnow FD, Noda LK, Goncalves NS, Costa I, de Melo HG, Crayston JA, and Franco CV, (2004)Electroreductive polymerization of trans- $\mathrm{RuCl}_{2}$ (vpy) 4 on $\mathrm{Nd}$ Fe-B magnets: electrochemical impedance spectroscopy interpretation, Raman spectroscopy, X-ray photoelectron spectroscopy and scanning electron microscopy analysis. J. Solid State Electrochem. 8(4): p. 244.

[36] Sobral AVC, Ristow W, Domenech SC, and Franco CV, (2000)Characterization and corrosion behavior of injection molded 17-4 PH steel electrochemically coated with poly trans-dichloro(4-vinylpyridine)ruthenium. J. Solid State Electrochem. 4(7): p. 417.

[37] Bandeira MCE, Crayston JA, Concalves NS, Noda LK, Glidle A, and Franco CV, (2007)Electropolymerization of trans- $\mathrm{RuCl}_{2}$ (vpy) 4 complex-EQCM and Raman studies. J. Solid State Electrochem. 11(2): p. 231.

[38] Antony R, Tembe GL, Ravindranathan M, and Ram RN, (2000)Synthesis and catalytic property of poly(styrene-co-divinylbenzene) supported ruthenium(III)-2-aminopyridyl complexes. Eur. Polym. J. 36(8): p. 1579.

[39] Jandrey AC, de Aguiar AP, de Aguiar M, and de santa Maria LC, (2004)Thermodegradation of poly(2-vinylpyridine-co-styrene-co-divinylbenzene) and N-oxide derivatives. Thermochim. Acta. 424(1-2): p. 63.

[40] Creczynski-Pasa TB, Bonetti VR, Beirith A, Ckless K, Konzen M, Seifriz I, Paula MS, Franco CV, Wilhelm D, and Calixto JB, (2001)Complexes trans- $\mathrm{RuCl}_{2}($ nic) 4 and trans$\mathrm{RuCl}_{2}$ (i-nic) 4 as free radical scavengers. J. Inorg. Biochem. 86(2-3): p. 587.

[41] Meggers E, Atilla-Gokcumen GE, Bregman H, Maksimoska J, Mulcahy SP, Pagano N, and Williams DS, (2007)Exploring chemical space with organometallics: Ruthenium complexes as protein kinase inhibitors. Synlett. (8): p. 1177.

[42] Meggers E, (2009)Targeting proteins with metal complexes. Chem. Commun. (Cambridge, U. K.). (9): p. 1001. 
[43] Atilla-Gokcumen GE, Di Costanzo L, and Meggers E, (2011)Structure of anticancer ruthenium half-sandwich complex bound to glycogen synthase kinase 3 beta. J. Biol. Inorg. Chem. 16(1): p. 45.

[44] Wu CH, Wu DH, Liu X, Guoyiqibayi G, Guo DD, Lv G, Wang XM, Yan H, Jiang H, and $\mathrm{Lu} \mathrm{ZH}$, (2009)Ligand-Based Neutral Ruthenium(II) Arene Complex: Selective Anticancer Action. Inorg. Chem. 48(6): p. 2352.

[45] Zhang G, Wu CH, Ye HD, Yan H, and Wang XM, (2011)Nanoscaled carborane ruthenium(II)-arene complex inducing lung cancer cells apoptosis. J. Nanobiotechnology. 9.

[46] Sertchook H and Avnir D, (2003)Submicron silica/polystyrene composite particles prepared by a one-step sol-gel process. Chem. Mater. 15(8): p. 1690.

[47] Trindade T, O'Brien P, and Pickett NL, (2001)Nanocrystalline semiconductors: Synthesis, properties, and perspectives. Chem. Mater. 13(11): p. 3843.

[48] Bullions TA, Wei M, Porbeni FE, Gerber MJ, Peet J, Balik M, White JL, and Tonelli AE, (2002)Molecular dynamics in nanostructured polyimide-silica hybrid materials and their thermal stability. J. Polym. Sci., Part B: Polym. Phys. 40(10): p. 1056.

[49] Erdem B, Sudol ED, Dimonie VL, and El-Aasser MS, (2000)Encapsulation of inorganic particles via miniemulsion polymerization. I. Dispersion of titanium dioxide particles in organic media using OLOA 370 as stabilizer. J. Polym. Sci., Part A: Polym. Chem. 38(24): p. 4419.

[50] Erdem B, Sudol ED, Dimonie VL, and El-Aasser MS, (2000)Encapsulation of inorganic particles via miniemulsion polymerization. II. Preparation and characterization of styrene miniemulsion droplets containing $\mathrm{TiO}_{2}$ particles. J. Polym. Sci., Part A: Polym. Chem. 38(24): p. 4431.

[51] Erdem B, Sudol ED, Dimonie VL, and El-Aasser MS, (2000)Encapsulation of inorganic particles via miniemulsion polymerization. III. Characterization of encapsulation. J. Polym. Sci., Part A: Polym. Chem. 38(24): p. 4441.

[52] Tiarks F, Landfester K, and Antonietti M, (2001)Silica nanoparticles as surfactants and fillers for latexes made by miniemulsion polymerization. Langmuir. 17(19): p. 5775.

[53] Esteves ACC, Barros-Timmons A, Monteiro I, and Trindade T, (2005)Polymer encapsulation of $\mathrm{CdE}(\mathrm{E}=\mathrm{S}$, Se) quantum dot ensembles via in-situ radical polymerization in miniemulsion. J. Nanosci. Nanotechnol. 5(5): p. 766.

[54] Joumaa N, Lansalot M, Theretz A, and Elaissari A, (2006)Synthesis of quantum dottagged submicrometer polystyrene particles by miniemulsion polymerization. Langmuir. 22(4): p. 1810.

[55] Pereira AS, Rauwel P, Reis MS, Silva NJO, Barros-Timmons A, and Trindade T, (2008)Polymer encapsulation effects on the magnetism of EuS nanocrystals. J. Mater. Chem. 18(38): p. 4572.

[56] Martins MA, Neves MC, Esteves ACC, Girginova PI, Guiomar AJ, Amaral VS, and Trindade T, (2007)Biofunctionalized ferromagnetic CoPt 3 /polymer nanocomposites. Nanotechnology. 18(21). 
[57] Fleischhaker F and Zentel R, (2005)Photonic crystals from core-shell colloids with incorporated highly fluorescent quantum dots. Chem. Mater. 17(6): p. 1346.

[58] Fornes TD and Paul DR, (2003)Crystallization behavior of nylon 6 nanocomposites. Polymer. 44(14): p. 3945.

[59] Esteves ACC, Barros-Timmons AM, Martins JA, Zhang W, Cruz-Pinto J, and Trindade T, (2005)Crystallization behaviour of new poly(tetramethyleneterephthalamide) nanocomposites containing $\mathrm{SiO}_{2}$ fillers with distinct morphologies. Compos Part B Eng. 36(1): p. 51.

[60] Oriakhi CO, (2000)Polymer Nanocomposition Approach to Advanced Materials. J. Chem. Educ. 77(9): p. 1138.

[61] Rajeshwar K, De Tacconi NR, and Chenthamarakshan CR, (2001)Semiconductor-based composite materials: Preparation, properties, and performance. Chem. Mater. 13(9): p. 2765.

[62] Steigerwald ML and Brus LE, (1990)Semiconductor crystallites: A class of large molecules. Acc. Chem. Res. 23(6): p. 183.

[63] Fleming MS, Mandal TK, and Walt DR, (2001)Nanosphere-microsphere assembly: Methods for core-shell materials preparation. Chem. Mater. 13(6): p. 2210.

[64] Gilman JW, Jackson CL, Morgan AB, Harris R, Manias E, Giannelis EP, Wuthenow M, Hilton D, and Phillips SH, (2000)Flammability properties of polymer - Layered-silicate nanocomposites. Polypropylene and polystyrene nanocomposites. Chem. Mater. 12(7): p. 1866.

[65] Hsiue GH, Liu YL, and Liao HH, (2001)Flame-retardant epoxy resins: An approach from organic-inorganic hybrid nanocomposites. J. Polym. Sci., Part A: Polym. Chem. 39(7): p. 986.

[66] Sanchez C, Julian B, Belleville P, and Popall M, (2005)Applications of hybrid organicinorganic nanocomposites. J. Mater. Chem. 15(35-36): p. 3559.

[67] Zhang F, Zhang $\mathrm{H}$, and $\mathrm{Su} \mathrm{Z,} \mathrm{(2008)In} \mathrm{situ} \mathrm{preparation} \mathrm{of} \mathrm{Mg}(\mathrm{OH})_{2} /$ polystyrene nanocomposite via soapless emulsion polymerization. Polym. Bull. (Berlin). 60(2): p. 251.

[68] Segala K, Dutra RL, Franco CV, Pereira AS, and Trindade T, (2010)In Situ and Ex Situ Preparations of $\mathrm{ZnO} /$ Poly-\{trans- $\mathrm{RuCl}_{2}$ (vpy)4/styrene\} Nanocomposites. J. Braz. Chem. Soc. 21(10): p. 1986.

[69] Segala K, Dutra RL, de Oliveira EN, Rossi LM, Matos JR, Paula MMS, and Franco CV, (2006)Characterization of poly-\{trans- $\mathrm{RuCl}_{2}$ (vpy) 4 -styrene-4-vinylpyridine\} impregnated with silver nanoparticles in non aqueous medium. J. Braz. Chem. Soc. 17(8): p. 1679.

[70] Brus LE, (1984)Electron-electron and electron-hole interactions in small semiconductor crystallites - The size dependence of the lowest excited electronic state. J. Chem. Phys. 80(9): p. 4403. 
[71] Pesika NS, Stebe KJ, and Searson PC, (2003)Determination of the particle size distribution of quantum nanocrystals from absorbance spectra. Adv. Mater. 15(15): p. 1289.

[72] Bowler PG, (2004)Microbicidal Properties of a Silver-Containing Hydrofiber" Dressing Against a Variety of Burn Wound Pathogens. J. Burn Care Rehabil. 25(2): p. 192.

[73] Uygur F, Oncul O, Evinc R, Diktas H, Acar A, and Ulkuer E, (2009)Effects of three different topical antibacterial dressings on Acinetobacter baumannii-contaminated fullthickness burns in rats. Burns. 35(2): p. 270.

[74] Lalueza P, Monzon M, Arruebo M, and Santamaria J, (2011)Bactericidal effects of different silver-containing materials. Mater. Res. Bull. 46(11): p. 2070.

[75] Kong H and Jang J, (2008)Antibacterial properties of novel poly(methyl methacrylate) nanofiber containing silver nanoparticles. Langmuir. 24(5): p. 2051.

[76] Roe D, Karandikar B, Bonn-Savage N, Gibbins B, and Roullet J-B, (2008)Antimicrobial surface functionalization of plastic catheters by silver nanoparticles. J. Antimicrob. Chemother. 61(4): p. 869.

[77] Chopra I, (2007)The increasing use of silver-based products as antimicrobial agents: a useful development or a cause for concern? J. Antimicrob. Chemother. 59(4): p. 587.

[78] Franke S, Grass G, and Nies DH, (2001)The product of the ybdE gene of the Escherichia coli chromosome is involved in detoxification of silver ions. Microbiol. 147: p. 965.

[79] Dutra RL, Segala K, de Oliveira EMN, de Souza EP, Rossi LM, Matos JR, Noda LK, Paula MMS, and Franco CV, (2008)Preparation and characterization of the novels terpolymers of poly-\{trans- $\mathrm{RuCl}_{2}$ (vpy)4-styrene-divinylbenzene $\}$ and styrenedivinylbenzene-vinylpiridine impregnated with silver nanoparticles. Polym. Bull. (Berlin). 60(6): p. 809.

[80] Creighton JA, Blatchford CG, and Albrecht MG, (1979)Plasma resonance enhancement of raman-scattering by pyridine adsorbed on silver or gold sol particles of size comparable to the excitation wavelength. J. Chem. Soc., Faraday Trans. 75: p. 790.

[81] Lu AH, Salabas EL, and Schuth F, (2007)Magnetic nanoparticles: Synthesis, protection, functionalization, and application. Angew. Chem., Int. Ed. 46(8): p. 1222.

[82] Shevchenko EV, Talapin DV, Rogach AL, Kornowski A, Haase M, and Weller H, (2002)Colloidal synthesis and self-assembly of COPt3 nanocrystals. J. Am. Chem. Soc. 124(38): p. 11480.

[83] Ely TO, Pan C, Amiens C, Chaudret B, Dassenoy F, Lecante P, Casanove MJ, Mosset A, Respaud M, and Broto JM, (2000)Nanoscale Bimetallic CoxPt1-x Particles Dispersed in Poly(vinylpyrrolidone): Synthesis from Organometallic Precursors and Characterization. J. Phys. Chem. B. 104(4): p. 695.

[84] Kim JH, Kim J, Baek KH, Im DH, Kim CK, and Yoon CS, (2007)Fabrication of CoPt nanoparticles with high coercivity on a polymer film. Colloids Surf., A. 301(1-3): p. 419.

[85] Frommen C, Malik S, Wurfel JU, Rosner H, and Didschies C, (2004)Synthesis and magnetic properties of $\mathrm{CoPt}_{3}$ nanoparticle assemblies containing copper. Mater. Lett. 58(6): p. 953. 
[86] El-Boubbou K, Gruden C, and Huang X, (2007)Magnetic glyco-nanoparticles: A unique tool for rapid pathogen detection, decontamination, and strain differentiation. J. Am. Chem. Soc. 129(44): p. 13392.

[87] Widder KJ, Senyei AE, Ovadia H, and Paterson PY, (1979)Magnetic protein-A microspheres - Rapid method for cell-separation. Clin. Immunol. Immunopathol. 14(3): p. 395.

[88] Fievet F, Lagier JP, Blin B, Beaudoin B, and Figlarz M, (1989)Homogeneous and heterogeneous nucleations in the polyol process for the preparation of micron and submicron size metal particles. Solid State Ionics. 32-3: p. 198. 